\title{
An observing system simulation experiment for FORMOSAT-5/AIP probing topside ionospheric plasma irregularities by using DEMETER/IAP
}

\author{
Jann-Yenq Liu ${ }^{1,2, *}$, Yang-Yi Sun ${ }^{1}$, Chi-Kuang Chao ${ }^{1}$, Shih-Ping Chen ${ }^{1}$, and Michel Parrot ${ }^{3}$ \\ ${ }^{1}$ Institute of Space Science, National Central University, Taoyuan City, Taiwan \\ ${ }^{2}$ Center for Space and Remote Sensing Research, National Central University, Taoyuan City, Taiwan \\ ${ }^{3}$ LPCE/CNRS, Orleans, France
}

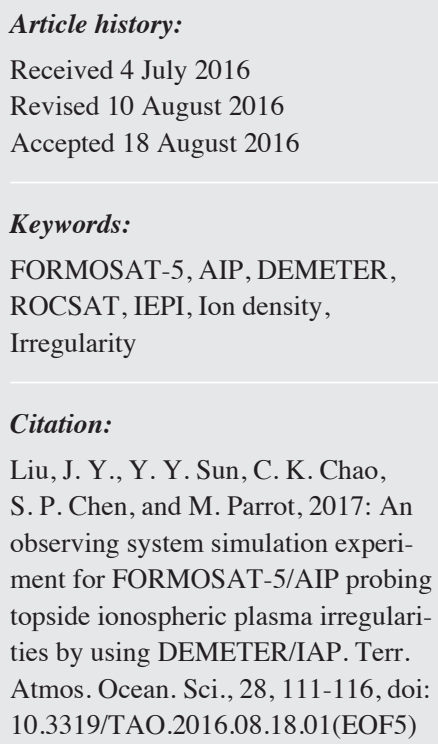

Received 4 July 2016

Revised 10 August 2016

Accepted 18 August 2016

Keywords:

FORMOSAT-5, AIP, DEMETER, ROCSAT, IEPI, Ion density, Irregularity

Citation:

Liu, J. Y., Y. Y. Sun, C. K. Chao, S. P. Chen, and M. Parrot, 2017: An observing system simulation experiment for FORMOSAT-5/AIP probing topside ionospheric plasma irregularities by using DEMETER/IAP. Terr. Atmos. Ocean. Sci., 28, 111-116, doi: 10.3319/TAO.2016.08.18.01(EOF5)

\begin{abstract}
The ion density probed by IAP (Instrument d'Analyse du Plasma) on board the DEMETER (Detection of Electro-Magnetic Emissions Transmitted from Earthquake Regions) satellite is used to find whether the science payload of Advanced Ionospheric Probe (AIP) on board FORMOSAT- 5 can be employed to observe space weather of ionospheric plasma irregularities. The low-latitude irregularities within $\pm 15^{\circ}$ dip latitudes of the DEMETER/IAP ion density are nighttime phenomena, and become prominent in the South America-Central Africa sector almost all year round, especially during May to August. The high-latitude irregularities of the DEMETER/ IAP ion density appear around $\pm 65^{\circ}$ dip latitude worldwide in both daytime and nighttime, and become very intense in the winter and the equinox month/hemisphere. DEMETER/IAP results show that FORMOSAT-5/AIP can be used to monitor space weather of ionospheric daytime/nighttime plasma irregularities in not only the lowbut also high-latitude ionosphere.
\end{abstract}

\section{INTRODUCTION}

FORMOSAT-5 is a remote sensing satellite scheduled to launch by the end of 2016 , anticipated to fly in a $98.28^{\circ}$ inclination sun-synchronous circular orbit at $720 \mathrm{~km}$ altitude near the 1030 LT (local time) and 2230 LT sectors. AIP (Advanced Ionospheric Probe) is an all-in-one plasma sensor to install on the FORMOSAT-5 satellite with a sampling rate up to $8192 \mathrm{~S} \mathrm{~s}^{-1}$ (Sample per second) to measure the ion density, ion velocity and ion/electron temperature over a wide range of spatial scales in a time-sharing way (Lin et al. 2017). This allows scientists worldwide (both low- and high-latitude) to monitor space weather of ionospheric plasma irregularities in both daytime and nighttime with much higher accuracy. The FORMOSAT-5/AIP science mission is to explore ionospheric space weather (Chen et al. 2017) and detect seismo-ionospheric precursors associated with

\footnotetext{
* Corresponding author

E-mail:tigerjyliu@gmail.com
}

large earthquakes (Liu and Chao 2017). One of the important space weather issues is to monitor ionospheric plasma irregularities that affect high accuracy positioning, navigation, and communication applications (cf. Sun et al. 2013, 2015; Liu et al. 2016).

The most comprehensive plasma irregularity observation in the low-latitude ionosphere has been carried out by the Ionospheric Plasma and Electrodynamics Instrument (IPEI) onboard ROCSAT (i.e., FORMOSAT-1), which orbits at $600 \mathrm{~km}$ altitude with $35^{\circ}$ inclination. This satellite circulates around the Earth every $97 \mathrm{~min}$, transmitting collected data to Taiwan's receiving stations approximately six times a day during 1999 - 2004. Although, ROCSAT/IPEI conclusively observes global distributions of low-latitude ionospheric irregularities (cf. Su et al. 2006, 2010), highlatitude ionospheric irregularities have not yet been studied in detail. AIP on board FORMOSAT-5 is a next version and advanced generation science payload of IPEI on 
board ROCSAT. The inclination $98.28^{\circ}$ of FORMOSAT- 5 allows us observing global distributions of both low- and high-latitude ionospheric plasma irregularities near 1030 and $2230 \mathrm{LT}$.

This paper explores whether FORMOSAT-5/AIP can be used to detect ionospheric plasma irregularities at $720 \mathrm{~km}$ altitude or not. We conduct an observing system simulation experiment (OSSE) using the ion density probed by IAP (Instrument d'Analyse du Plasma) onboard DEMETER (Detection of Electro-Magnetic Emissions Transmitted from Earthquake Regions) satellite and cross compare with that observed by ROCSAT/IPEI.

\section{EXPERIMENT DESIGN AND OBSERVATION}

The DEMETER satellite is a micro-satellite that observes the region within $65^{\circ}$ geomagnetic latitude in a $680 \mathrm{~km}$ altitude, $98.3^{\circ}$ inclination orbit. It is also a sun-synchronous satellite that passes in almost the same local time everywhere at 1030 and 2230 LT. DEMETER carries 6 payloads. We focus on IAP detecting the plasma density and the ion composition (Berthelier et al. 2006). Since both have sun-synchronous orbits at $680 / 720 \mathrm{~km}$ altitude in the 1030 and 2230 LT sectors, DEMETER/IAP provides an excellent opportunity to conduct the OSSE for FORMOSAT-5/ AIP observing low-latitude topside ionospheric plasma irregularities. For the cross comparison we examine the ionospheric plasma irregularity using the $\sigma$ index proposed by Su et al. (2006). Here, the $\sigma$ index is given as,

$$
\sigma=\frac{\left[\frac{1}{10} \sum_{i=1}^{10}\left(\log n_{i}-\log n_{o i}\right)^{2}\right]^{1 / 2}}{\frac{1}{10} \sum_{i=1}^{10} \log n_{o i}}
$$

where $n_{i}$ is the ion density at each second and $n_{o i}$ is the linearly fitted value of $10-\mathrm{sec}$ data. Su et al. (2006) used $\sigma \geq 0.3 \%$ as the threshold to find the occurrence probability of ionospheric plasma irregularities from the ROCSAT 1 -sec ion density. Figure 1 displays two examples of the ion density along the DEMETER track of about $45^{\circ} \mathrm{W}$ and the associated $\sigma$ index computed with $\mathrm{Su}$ et al. (2006).

Figure 2 depicts the seasonal and geographical distributions of the occurrence probability near $2230 \mathrm{LT}$ that the low-latitude irregularities probed by DEMETER/IAP develop within $\pm 15^{\circ}$ dip latitudes constantly from $0-60^{\circ} \mathrm{W}$ (South America-Central Africa sector), especially prominent in May to August, during 2006 - 2010. The most intense ionospheric plasma irregularities appear about $\pm 65^{\circ}$ dip latitude in the high-latitude ionosphere. It is interesting to find that the high-latitude ionospheric plasma irregularities appear prominently in the winter hemisphere (i.e., the Northern hemisphere in October to February, and the South- ern hemisphere in April to August), but become equally pronounced in both hemispheres in March and September (equinox months).

Figure 3 displays the geographical distributions of the occurrence probability of low-latitude nighttime (1900 2400 LT) plasma irregularities probed by ROCSAT/IPEI in various months during 1999 - 2002. The pronounced pattern generally follows the magnetic equator over the twelve months, taking place from $10-70^{\circ} \mathrm{W}$ longitude (South American-Atlantic sector) in November-January; from $15^{\circ} \mathrm{W}-40^{\circ} \mathrm{E}$ and $120-240^{\circ} \mathrm{E}$ longitude (African and Pacific sector) in April-August; and from $120^{\circ} \mathrm{W}-120^{\circ} \mathrm{E}$ longitude (Atlantic sector) in February to March and September to October, respectively. In fact, the irregularities spread over the entire magnetic equator during the equinox months.

\section{DISCUSSION AND CONCLUSION}

Figures 2 and 3 show that the longitudinal distributions of low-latitude ionospheric plasma irregularities detected by DEMETER/IAP and ROCSAT/IPEI are different from May to August. Note that the main difference between the two satellites is the inclination, $35^{\circ}$ (a quasi-magnetic zonal direction) for ROCSAT and $98.3^{\circ}$ (a quasi-magnetic meridional direction) for DEMETER. The large scale equatorial ionospheric disturbance structure, such as plasma bubbles, is elongated along the magnetic field lines. Because of the geomagnetic control, the scale length in the magnetic meridional direction is much greater than that in the zonal direction (Kelley 2009; Retterer 2010; Yokoyama et al. 2014). The $\sigma$ index in Eq. (1) is computed every $10 \mathrm{~s}$. The DEMETER and ROCSAT satellite speeds are about $7-8 \mathrm{~km} \mathrm{~s}^{-1}$, and therefore the $\sigma$ index can be employed to detect ionospheric plasma irregularities approximately smaller than about $80 \mathrm{~km}$.

Figure 4 is the Fourier analysis on the ion density within $\pm 15^{\circ}$ magnetic latitudes probed by DEMETER/IAP. It is surprising to see that the longitudinal distributions of the spectrum amplitude agree with those of the irregularity occurrence probability observed by ROCSAT/IPEI, shown in Fig. 3. The irregularity occurrence probability distribution and the spectrum amplitude observed by DEMETER/ IAP disagrees with each other, which suggests that the index computed using Eq. (1) may need to be redesigned for detecting low-latitude ionospheric plasma irregularities probed by sun-synchronous circular orbit satellites.

Low-latitude ionospheric plasma irregularities have been intensively examined, and found to be nighttime phenomena (Kelley 2009). Here, high inclination satellites, such as DEMETER and FORMOSAT-5, provide an opportunity to probe global ionospheric plasma irregularities in the high-latitude ionosphere in both nighttime at $2230 \mathrm{LT}$ and daytime at 1030 LT. Figure 5 displays the irregularity occurrence probability distribution probed by DEMETER/IAP at 1030 LT. No prominent irregularity was found occurring 

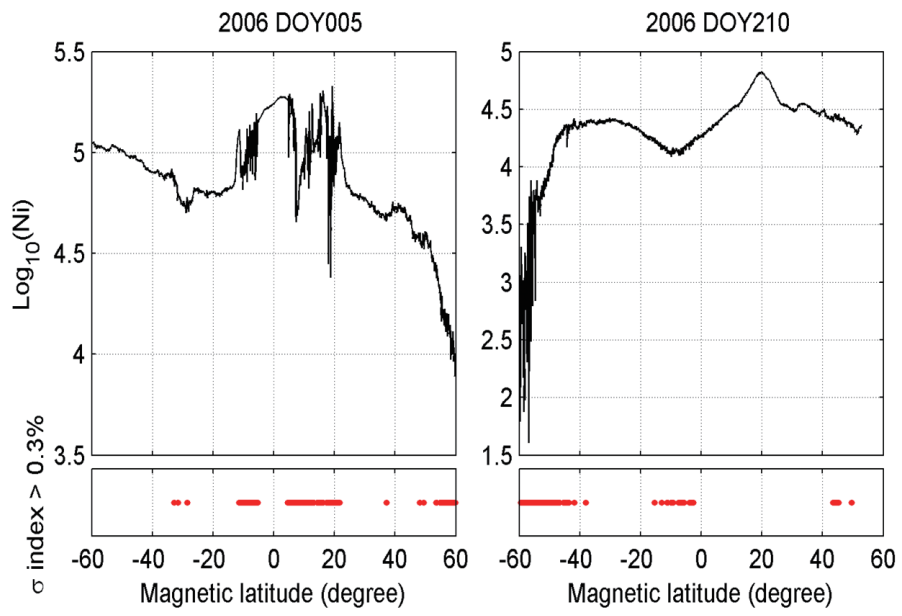

Fig. 1. Latitudinal structures of ion density probed by DEMETER/IAP near $45^{\circ} \mathrm{W}$ in 5 January and 29 July 2006 (top panel). Red dots ( $\sigma$ index $>$ $0.3 \%$ ) indicate the associated occurrence of irregularities (bottom panel). (Color online only)
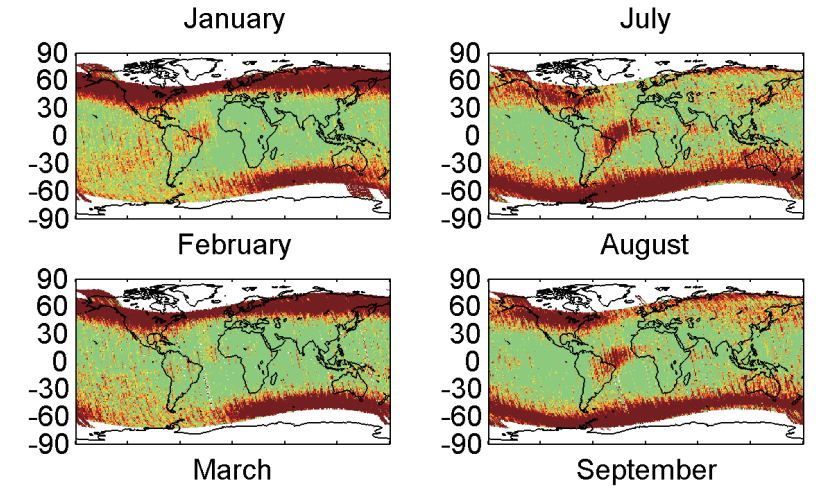

\section{Probability}
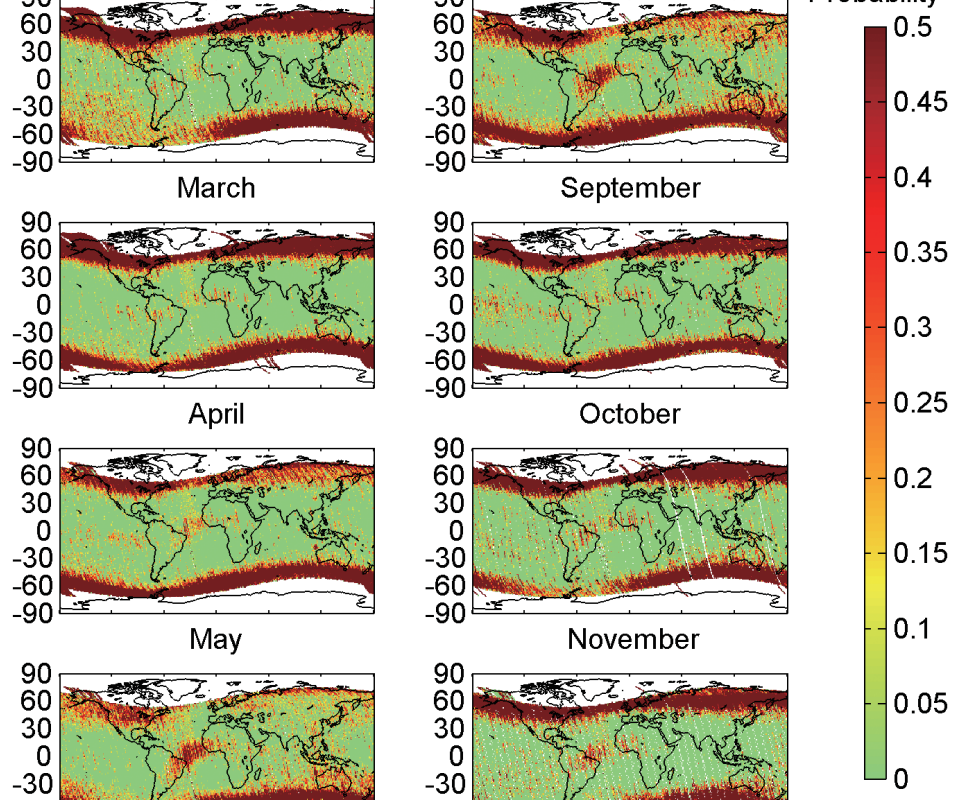

.35
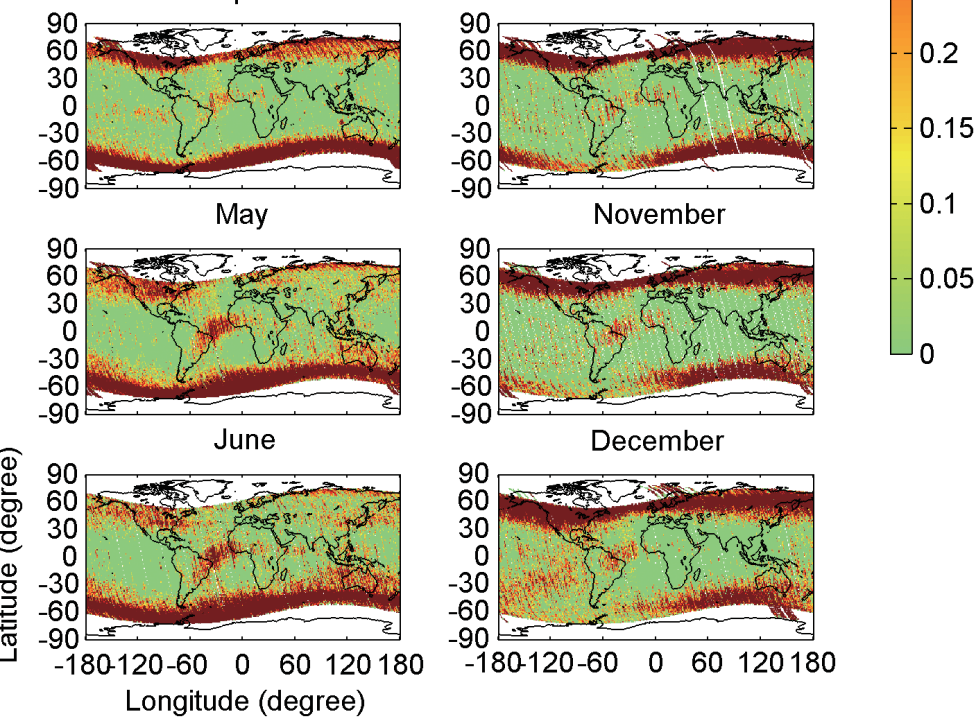

Fig. 2. Geographical ionospheric irregularity occurrence probability distributions in the ion density probed by DEMETER/AIP near 2230 LT during the period of $2006-2010$. The spatial resolution of these maps is $1^{\circ}$ in both the geographic longitude and latitude. The probability is the number of detected irregularities divided by the total data points in each lattice. (Color online only) 

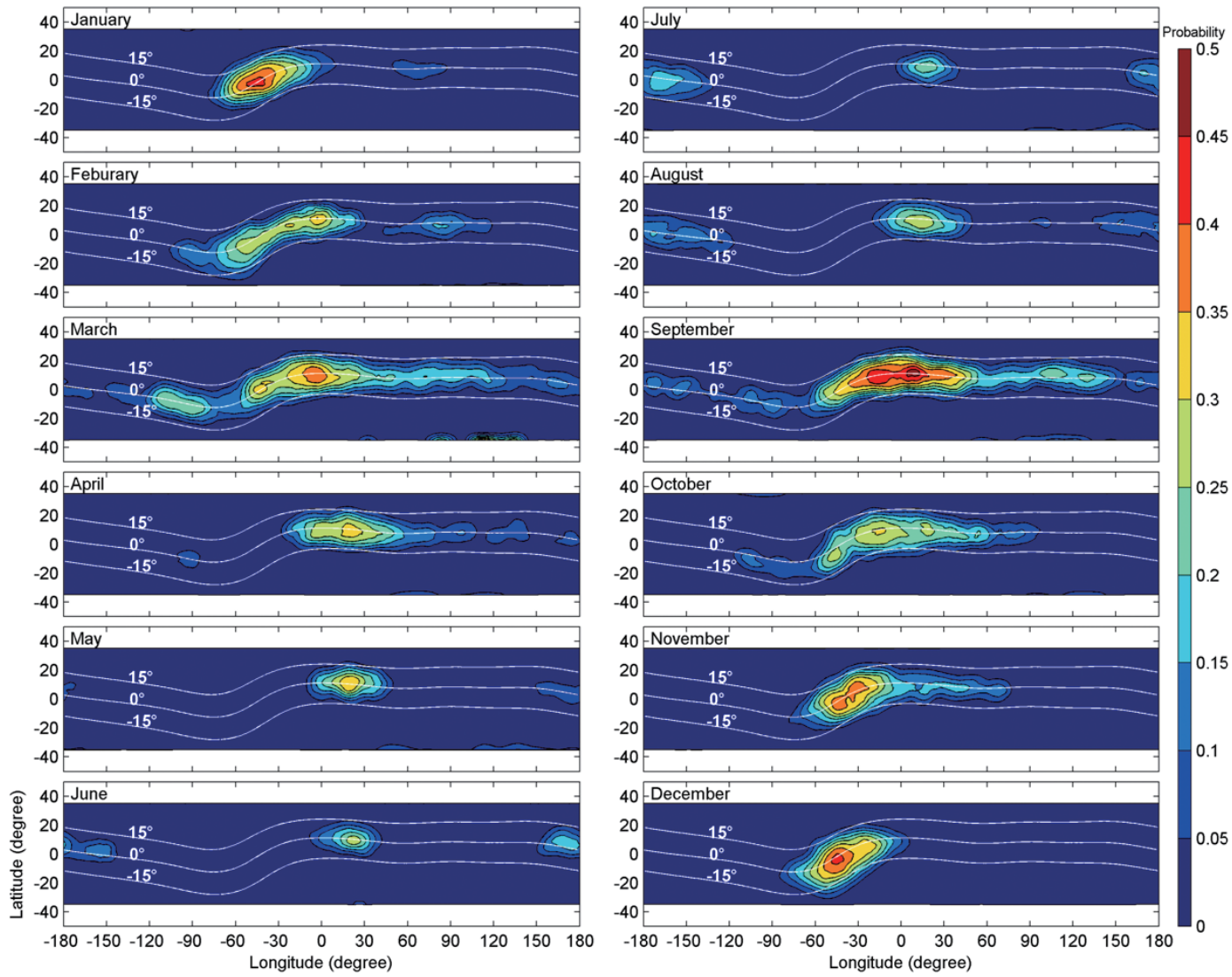

Fig. 3. Geographical ionospheric irregularity occurrence probability distribution in the ion density observed by ROCSAT/IPEI from $1999-2002$ (Color online only)
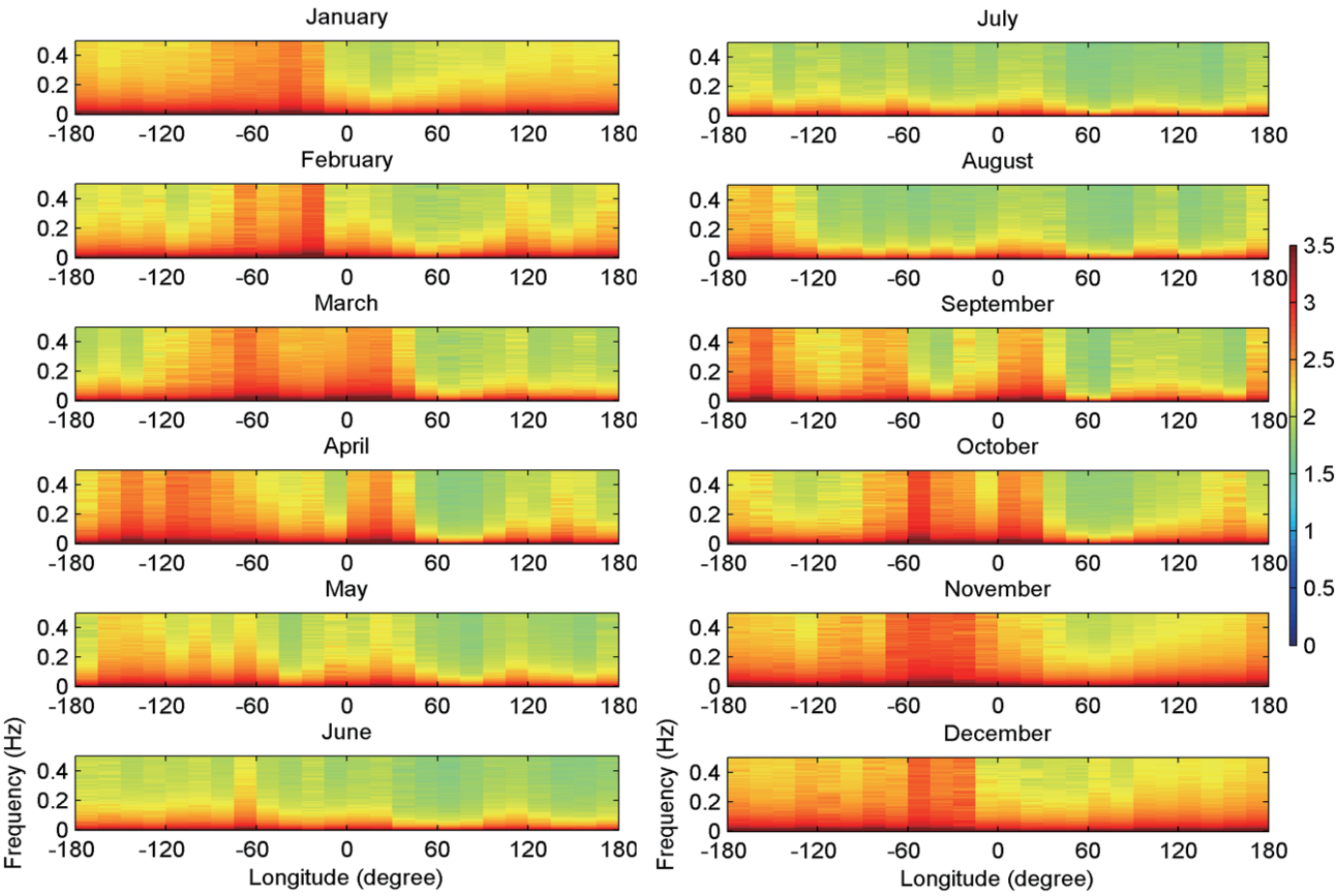

Fig. 4. Fourier spectra of the DEMETER/AIP ion density within $\pm 15^{\circ}$ magnetic latitude near 2230 LT during the period of $2006-2010$. (Color online only) 


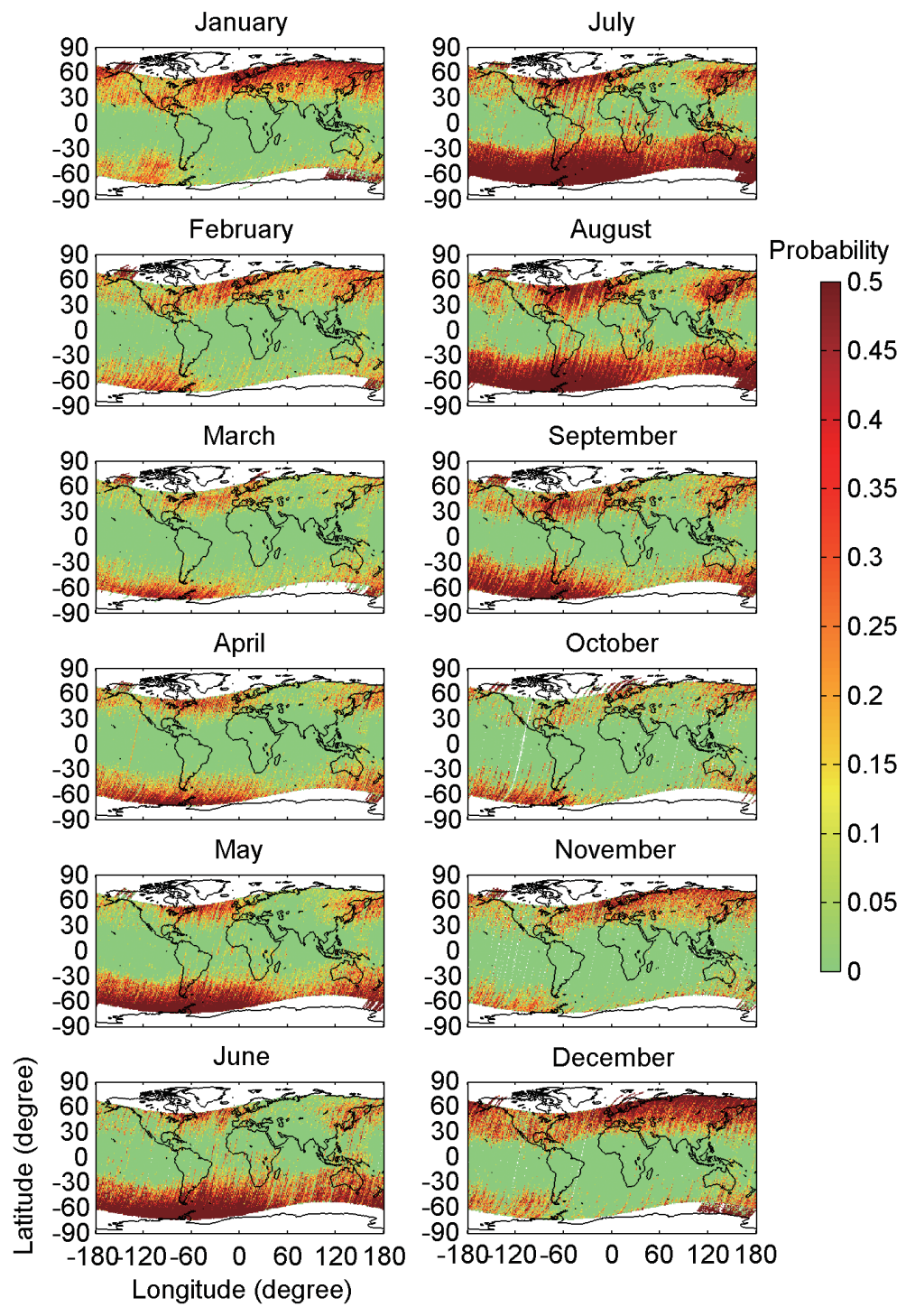

Fig. 5. Similar to Fig. 2 but at 1030 LT. (Color online only)

in the low-latitude ionosphere, which agrees with existing radar and satellite observations (Kelley 2009). Meanwhile, for the high-latitude ionosphere, the irregularity occurrence probability distributions near $1030 \mathrm{LT}$ are very similar to those near 2230 LT, shown in Fig. 2.

The irregularity occurrence probability detected by DEMETER at high latitudes is much higher than that at low latitudes. This could be due to the fact that the DEMETER data used in this study were taken during 2006 - 2010, a period of deep solar minimum. Note that the ionospheric irregularity occurrence probability depends on solar activity and is higher at equatorial latitudes than at high latitudes during solar maximum. However, the occurrence probability is higher at high latitudes than at low latitudes during solar minimum (e.g., Basu et al. 1988).

In conclusion, the OSSE of DEMETER/IAP shows that FOROMSAT-5/AIP can be used to study the iono- sphere plasma irregularity of the globe near 1030 and 2230 LT. It is found that different approaches might yield different results in studying ionospheric plasma irregularities. The spectrum analysis can robustly detect ionospheric plasma irregularities, while the occurrence probability approach might need to be redesigned for the upcoming FORMOSAT-5/AIP mission.

Acknowledgements This study is supported by a grant from the Ministry of Science and Technology to National Central University, MOST 104-2628-M-008-001, as well as by International Team of "Ionospheric Space Weather Studied by RO and Ground-based GPS TEC Observations" selected by ISSI-Bern in 2016. The authors gratefully acknowledge the Common Data Service Platform of Atmospheric Science Data in Taiwan - Taiwan Space Science Database for publishing ROCSAT/IPEI data (http://sdbweb.ss.ncu.edu.tw/ 
ipei download.html) and Centre National d'Etudes Spatiales NCES for providing DEMETER/IAP data (https://demeter. cnes.fr/en/DEMETER/index.htm).

\section{REFERENCES}

Basu, S., E. MacKenzie, and S. Basu, 1988: Ionospheric constraints on VHF/UHF communications links during solar maximum and minimum periods. Radio Sci., 23, 363-378, doi: 10.1029/RS023i003p00363. [Link]

Berthelier, J. J., M. Godefroy, F. Leblanc, E. Seran, D. Peschard, P. Gilbert, and J. Artru, 2006: IAP, the thermal plasma analyzer on DEMETER. Planet. Space Sci., 54, 487-501, doi: 10.1016/j.pss.2005.10.018. [Link]

Chen, C. H., C. C. H. Lin, J. Y. Liu, T. Matsuo, and W. H. Chen, 2017: The impact of FORMOSAT-5/ AIP observations on the ionospheric space weather. Terr. Atmos. Ocean. Sci., 28, 129-137, doi: 10.3319/ TAO.2016.09.30.01(EOF5). [Link]

Kelley, M. C., 2009: The Earth's Ionosphere: Plasma Physics and Electrodynamics, $2^{\text {nd }}$ Edition, Academic Press, San Diego, 576 pp.

Lin, Z. W., C. K. Chao, J. Y. Liu, C. M. Huang, Y. H. Chu, C. L. Su, Y. C. Mao, and Y. S. Chang, 2017: Advanced Ionospheric Probe scientific mission onboard FORMOSAT-5 satellite. Terr. Atmos. Ocean. Sci., 28, 99110, doi: 10.3319/TAO.2016.09.14.01(EOF5). [Link]

Liu, J. Y. and C. K. Chao, 2017: An observing system simulation experiment for FORMOSAT-5/AIP detecting seismo-ionospheric precursors. Terr. Atmos. Ocean. Sci., 28,117-127, doi: 10.3319/TAO.2016.07.18.01(EOF5). [Link]

Liu, J. Y., S. P. Chen, W. H. Yeh, H. F. Tsai, and P. K. Rajesh, 2016: Worst-case GPS scintillations on the ground estimated from radio occultation observations of FORMOSAT-3/COSMIC during 2007-2014. Surv. Geophys., 37, 791-809, doi: 10.1007/s10712-0159355-x. [Link]

Retterer, J. M., 2010: Forecasting low-latitude radio scintillation with 3-D ionospheric plume models: 1 . Plume model. J. Geophys. Res., 115, A03306, doi: 10.1029/2008JA013839. [Link]

Su, S. Y., C. H. Liu, H. H. Ho, and C. K. Chao, 2006: Distribution characteristics of topside ionospheric density irregularities: Equatorial versus midlatitude regions. J. Geophys. Res., 111, A06305, doi: 10.1029/2005JA011330. [Link]

Su, S. Y., M. Q. Chen, C. K. Chao, and C. H. Liu, 2010: Global, seasonal, and local time variations of ion density structure at the low-latitude ionosphere and their relationship to the postsunset equatorial irregularity occurrences. J. Geophys. Res., 115, A02309, doi: 10.1029/2009JA014339. [Link]

Sun, Y. Y., T. Matsuo, E. A. Araujo-Pradere, and J. Y. Liu, 2013: Ground-based GPS observation of SED-associated irregularities over CONUS. J. Geophys. Res., 118, 2478-2489, doi: 10.1029/2012JA018103. [Link]

Sun, Y. Y., J. Y. Liu, C. K. Chao, and C. H. Chen, 2015: Intensity of low-latitude nighttime F-region ionospheric density irregularities observed by ROCSAT and ground-based GPS receivers in solar maximum. $J$. Atmos. Sol.-Terr. Phys., 123, 92-101, doi: 10.1016/j. jastp.2014.12.013. [Link]

Yokoyama, T., H. Shinagawa, and H. Jin, 2014: Nonlinear growth, bifurcation, and pinching of equatorial plasma bubble simulated by three-dimensional high-resolution bubble model. J. Geophys. Res., 119, 10474-10482, doi: 10.1002/2014JA020708. [Link] 